\title{
BMJ Open Results from a dietary survey in an Indian T2DM population: a STARCH study
}

\author{
Shashank R Joshi, ${ }^{1}$ Anil Bhansali, ${ }^{2}$ Sarita Bajaj, ${ }^{3}$ Subodh S Banzal, ${ }^{4}$ \\ Mala Dharmalingam, ${ }^{5}$ Shachin Gupta, ${ }^{6}$ Satinath Mukhopadhyay, ${ }^{7}$ Parag R Shah, ${ }^{8}$ \\ Rakesh Sahay, ${ }^{9}$ Swapan Sarkar, ${ }^{10}$ Pravin V Manjrekar, ${ }^{11}$ Rahul T Rathod, ${ }^{11}$ \\ Shilpa S Joshi ${ }^{12}$
}

To cite: Joshi SR, Bhansali A, Bajaj S, et al. Results from a dietary survey in an Indian T2DM population: a STARCH study. BMJ Open 2014:4:e005138. doi:10.1136/ bmjopen-2014-005138

- Prepublication history for this paper is available online. To view these files please visit the journal online (http://dx.doi.org/10.1136/ bmjopen-2014-005138).

Received 27 February 2014 Revised 16 August 2014 Accepted 10 September 2014

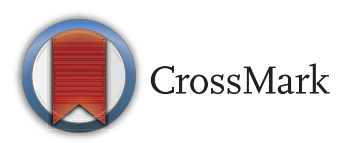

For numbered affiliations see end of article.

Correspondence to Dr Shashank R Joshi; shashank.sr@gmail.com

\section{ABSTRACT}

Objective: To assess the dietary total and complex carbohydrate (CHO) contents in type-2 diabetes mellitus (T2DM) participants in India.

Setting: We enrolled 796 participants in this crosssectional, single-visit, multicentre, two-arm, single-country survey. Participants were enrolled from 10 specialty India.

Participants: A total of 796 participants (Asian) were enrolled in this study (385, T2DM and 409, non-T2DM). Key inclusion criteria-male or female $\geq 18$ years, diagnosed with T2DM $\geq 12$ months (T2DM), and not on any diet plan (non-T2DM).

Study outcome: Primary outcome was to find out the percentage of total energy intake as simple and complex $\mathrm{CHO}$ from total $\mathrm{CHO}$. Secondary outcomes were to find the differences in percentage of total energy intake as simple $\mathrm{CHO}$, complex $\mathrm{CHO}$, proteins and fats between T2DM and non-T2DM groups. The percentage of T2DM participants adhering to diet plan and showing glycaemic controls were also examined.

Results: The mean (SD) of total calorie intake per day (Kcal) was 1547 (610, 95\% Cl 1486 to 1608) and 2132 (1892, 95\% Cl 1948 to 2316), respectively, for T2DM and non-T2DM groups. In the T2DM group ( $n=385)$, the mean (SD) percentage of total energy intake as total $\mathrm{CHO}$, complex $\mathrm{CHO}$ and simple $\mathrm{CHO}$ was $64.1 \pm 8.3(95 \% \mathrm{Cl} 63.3$ to 64.9$), 57.0 \pm 11.0(95 \% \mathrm{Cl} 55.9$ to 58.1$)$ and $7.1 \pm 10.8$ $(95 \% \mathrm{Cl} 6.0$ to 8.2$)$, respectively. The mean (SD) percentage of complex $\mathrm{CHO}$ intake from total $\mathrm{CHO}$ was $89.5 \pm 15.3(95 \% \mathrm{Cl} 88.0$ to 91.1$)$. The mean (SD) total protein/fat intake per day (g) was 57.1 (74.0)/37.2 (18.6) and 57.9 (27.2)/55.3 (98.2) in T2DM and non-T2DM groups, respectively.

Conclusions: Our study shows that $\mathrm{CHO}$ constitutes $64.1 \%$ of total energy from diet in T2DM participants, higher than that recommended in India. However, our findings need to be confirmed in a larger epidemiological survey.

Trial registration number: NCT01450592 \& Clinical Trial Registry of India: CTRI/2012/02/002398.

\section{INTRODUCTION}

According to a recent scenario, diabetes is becoming a global public health problem, endocrinology/dialectology centres from five regions of

\section{Strength and limitations of this study}

- The study for the first time reports the dietary habits of type-2 diabetes mellitus (T2DM) participants from across India.

- The study neutralises the myths associated with differences in dietary habits in different regions of India.

- The dietary habits of T2DM participants are not much different from those of non-T2DM participants.

- A possible limitation of the study includes the small sample size and the possibility of measurement error of diet and covariates.

- Population flow was mostly from specialty endocrinology/diabetology centres from urban areas.

especially in India. Obesity, especially central obesity, and increased visceral fat due to physical inactivity and consumption of highcalorie/high-fat and high-sugar diets are major contributing factors for it. ${ }^{1}$ In India, as urbanisation and economic growth occur, there are major deviations in the dietary pattern that are influenced by varied cultural and social customs. Environmental and lifestyle changes resulting from industrialisation and migration to an urban environment from rural settings may be responsible to a large extent in contributing to the epidemic of type-2 diabetes mellitus (T2DM) in Indians. $^{2}$

Barring a few smaller studies ${ }^{3}{ }^{4}$ from the southern part of India, we do not have any studies that document the dietary contents of patients with T2DM from across India. There was a need to conduct a dietary survey considering the diverse dietary food habits in various parts of India. The objective of this study (STARCH: Study To Assess the dietaRy CarboHydrate content of Indian type-2 diabetes population) was to assess the total and complex carbohydrate $(\mathrm{CHO})$ contents in the daily diet of T2DM participants. Our study not only provides preliminary information on the dietary carbohydrate, fat and 
protein contribution in food consumed by T2DM participants but also shows how it compares with non-T2DM participants from pan India.

\section{RESEARCH DESIGN AND METHODS}

\section{Study design and study participants}

Our study was an exploratory cross-sectional, single-visit, two-arm, multicentre, single-country survey. Study participants were enrolled (from March 2012 to September 2012) from 10 sites across all regions of India, viz; East, North, West, South and central, considering different dietary patterns. Participants were enrolled from endocrinology/diabetology clinics/hospitals with clinical research facilities during routine outpatient visits. Study participants were not provided with any incentives for participation in the study. Participants aged $\geq 18$ years of either sex, diagnosed with T2DM for at least 12 months, were eligible in the T2DM group, whereas participants not on any diet plan or dietary advice and who visited for acute illnesses/conditions that do not affect inclusion in the survey were included in the non-T2DM group. Moreover, non-T2DM participants were matched to T2DM participants with respect to age, sex and centre. Patients with specific comorbidities that may impact daily diet, with chronic diseases, or a weight management plan that includes dietary modifications or dietary alterations were excluded from the study. All participants provided written informed consent.

\section{Dietary survey methodology}

A dietary survey form, a 3-day dietary recall, and a validated Food Frequency Questionnaire (FFQ) were completed by a qualified dietitian or trained study coordinator. Dietary assessment included general dietary information (vegetarian or mixed), status of diet plan advised by the physician, and information about dietary patterns for both groups with the help of the dietary survey form, which included questions about the diet consumed during two typical working days and during one typical weekend day (usually Sunday). The final dietary assessment was done using the 3-day dietary recall data.

\section{Primary and secondary outcomes}

Primary outcome variables were the percentage of total energy intake as total $\mathrm{CHO}$ and complex $\mathrm{CHO}$ intake from total $\mathrm{CHO}$ in the T2DM group. The percentage of total energy intake from $\mathrm{CHO}$ was calculated as the sum of percentage of energy intake from complex $\mathrm{CHO}$ and simple CHO. Secondary outcome variables include the difference in the percentage of total energy intake as total, complex and simple $\mathrm{CHO}$, proteins and fats between T2DM and non-T2DM participants, percentage of patients with T2DM who adhere to the diet plan, glycaemic control as per American Diabetes Association (ADA) criteria $^{5}$ (glycated hemoglobin (HbA1c) $<7 \%$, fasting blood glucose (FBG) between 70 and
$130 \mathrm{mg} / \mathrm{dL}$, postprandial blood glucose (PPBG) $<180 \mathrm{mg} / \mathrm{dL}$ ) and the utilisation pattern of antidiabetic drugs.

\section{Statistical analysis and evaluations}

It was assumed that at least $50 \%$ of the total energy intake comes from $\mathrm{CHO}$ and at least $50 \%$ of the complex $\mathrm{CHO}$ intake comes from total $\mathrm{CHO}$ in T2DM participants. Thus, 385 T2DM participants were required to achieve an allowable error of $5 \%$ where the allowable error is half the width of a $95 \%$ CI. Taking missing data into consideration, we planned to conduct the survey with a total of 400 participants in each group. All analyses were performed on the eligible participants. The primary descriptive analysis of the data was performed using basic summary statistics. Further descriptive measures such as $\mathrm{n}$, mean, median, $\mathrm{SD}$, first quartile (Q1), third quartile (Q3), minimum and maximum were calculated for continuous variables. Percentages were calculated based on non-missing values. Frequency and percentage were calculated for categorical variables. For continuous variables, the mean change was compared statistically between T2DM and non-T2DM groups using either the independent $\mathrm{t}$ test or the Mann-Whitney $\mathrm{U}$ test based on normality of the data. The tests were carried out at a $5 \%$ level of significance and a $p$ value $\leq 0.05$ was considered as significant. Other comparisons specified in the secondary variables were carried out similarly. As per recommendations of the National Institute of Nutrition ${ }^{6}$ (NIN) and Indian Consensus Guideline $^{7}$ for Healthy Eating, a balanced diet should provide approximately $50-60 \%$ of total calories from $\mathrm{CHO}$ (preferably from complex $\mathrm{CHO}$ ), approximately $10-15 \%$ calories from proteins, and approximately 20 $30 \%$ calories from visible and invisible fats. Data were stratified as per CHO consumption: below NIN recommendation $(<50 \%)$, as per recommendation $(50-60 \%)$, and above recommendation $(>60 \%)$ to capture the natural distribution of patients within these stratifications. In addition, we also compared the findings with the WHO Expert group recommendations, that is, total CHO should provide $55-75 \%$ total energy and that free sugars should provide less than $10 \%$ energy. ${ }^{8}$ For categorical variables, the number and percentage of participants were considered. Continuous data are presented in this article as the mean and SD. Statistical evaluations were performed using the software SAS, V.9.1.3.

\section{RESULTS}

\section{Demographics and lifestyle characteristics}

A total of 796 participants were enrolled in the study; of those, two were screen failures and no participant declined to participate in our study. The remaining 794 participants (385 in the T2DM group and 409 in the non-T2DM group) completed the survey. Region-wise recruitment was as follows: north region $(n=160)$, east region $(n=180)$, south region $(n=158)$, west region 
$(\mathrm{n}=116)$, and central region $(\mathrm{n}=180)$. The demographic characteristics of the analysed participants are summarised in table 1. The mean (SD) age of the T2DM group was 53.4 (11.16) years and of the non-T2DM group was 42.5 (12.55) years. Of the 794 participants, $195(50.6 \%)$ and $175(42.8 \%)$ male participants were from T2DM and non-T2DM groups, respectively. The mean (SD) duration of diabetes (years) was 8.7 (5.95). The mean (SD) body mass index (BMI; $\mathrm{kg} / \mathrm{m}^{2}$, mean (SD)) in T2DM and non-T2DM groups was $26.4(4.4)$ and 26.7 (5), respectively. The region-wise BMI $\left(\mathrm{kg} / \mathrm{m}^{2}\right.$, mean $\left.(\mathrm{SD})\right)$ was 25.06 (3.7) and 25.22 (3.53) for the east region, 26.15 (4.4) and 30.87 (7.1) for the west region, 26.79 (4.3) and 25.9 (3.8) for the north region, 26.61 (3.5) and 25.66 (3.6) for the south region, and 26.87 (5.0) and 26.25 (4.4) for the central region in the T2DM and non-T2DM groups, respectively. The diet in T2DM and non-T2DM groups was composed of nearly equal $( \pm 5 \%)$ distribution of vegetarian and mixed diet (vegetarian plus non-vegetarian). In T2DM $(n=385)$ and non-T2DM groups $(n=409), 248$ $(64.4 \%)$ and $176(43 \%)$ participants were doing exercise. Among them, 228 (91.9\%; $\mathrm{n}=248)$ and 150 (85.2\%; $\mathrm{n}=176$ ) were reported to be doing exercise regularly in T2DM and non-T2DM groups, respectively; 40.3\% $(\mathrm{n}=155)$ and $59.2 \% \quad(\mathrm{n}=228$, data not available for two participants) in the T2DM group reported active and sedentary lifestyles, respectively.

\section{Primary and secondary outcomes}

In the T2DM group $(\mathrm{n}=385)$, the mean $(\mathrm{SD})$ percentage of total energy intake as total $\mathrm{CHO}$ was $64.1 \pm 8.3$ (95\% CI 63.3 to 64.9 ), as complex $\mathrm{CHO}$ was $57.0 \pm 11.0$ (95\% CI 55.9 to 58.1 ) and as simple $\mathrm{CHO}$ was $7.1 \pm 10.8$

\begin{tabular}{|c|c|c|}
\hline Parameters & $\begin{array}{l}\text { T2DM } \\
(n=385)\end{array}$ & $\begin{array}{l}\text { Non-T2DM } \\
(n=409)\end{array}$ \\
\hline Age (years, mean (SD)) & $53.4(11.16)$ & $42.5(12.55)$ \\
\hline \multicolumn{3}{|l|}{ Gender, $\mathrm{n}(\%)$} \\
\hline Male & $195(50.6)$ & $175(42.8)$ \\
\hline Female & $190(49.45)$ & $234(57.2)$ \\
\hline Body weight $(\mathrm{kg}), \mathrm{n}(\%)$ & $66.45(11.51)$ & $68.54(12.89)$ \\
\hline Body mass index $\left(\mathrm{kg} / \mathrm{m}^{2}\right), \mathrm{n}(\%)$ & $26.4(4.4)$ & $26.7(5.0)$ \\
\hline \multicolumn{3}{|l|}{ Socioeconomic status, $n^{*}(\%)$} \\
\hline Lower class & $8(2.1)$ & $1(0.2)$ \\
\hline Upper lower & $64(16.6)$ & $12(2.9)$ \\
\hline Lower middle & $54(14.0)$ & $39(9.5)$ \\
\hline Upper middle & $195(50.6)$ & $261(63.8)$ \\
\hline Upper class & $64(16.6)$ & $96(23.5)$ \\
\hline \multicolumn{3}{|l|}{ Diet, n (\%) } \\
\hline Vegetarian & $170(44.2)$ & $195(50.6)$ \\
\hline Mixed diet & $215(55.8)$ & $190(49.4)$ \\
\hline \multicolumn{3}{|c|}{$\begin{array}{l}\text { *The socioeconomic status was analysed using Kuppuswamy's } \\
\text { scale, which is based on three parameters: education of head of } \\
\text { family, occupation and family income (per month) }{ }^{9} \\
\text { T2DM, type-2 diabetes mellitus; non-T2DM, non-type-2 diabetes } \\
\text { mellitus. }\end{array}$} \\
\hline
\end{tabular}

(95\% CI 6.0 to 8.2 ). The mean (SD) percentage of complex $\mathrm{CHO}$ intake from total $\mathrm{CHO}$ was $89.5 \pm 15.3$ (95\% CI 88.0 to 91.1$)$. The overall summary and comparative analysis of T2DM and non-T2DM participants is presented in table 2. The region-wise mean $\mathrm{CHO}$ intake $(\%$, mean $(\mathrm{SD}))$ is summarised in table 3 .

In the non-T2DM group $(\mathrm{n}=409)$, the mean $(\mathrm{SD})$ percentage of total energy intake as total $\mathrm{CHO}$ was 66.8 $(9.1,95 \% \mathrm{CI})$, as complex $\mathrm{CHO}$ was $52.9(13.3,95 \%$ CI 51.6 to 54.2), and as simple CHO was 13.9 (13.8, 95\% CI 12.6 to 15.2 ). The region-wise $\mathrm{CHO}$ intake (in \%, mean (SD)) is summarised in table 4 .

The mean (SD) of total calorie intake per day (kcal) was 1547 (610, 95\% CI 1486 to 1608) and 2132 (1892, 95\% CI 1948 to 2316), respectively, for T2DM and non-T2DM groups. The mean (SD) of total CHO intake per day (g) was 246 (92, 95\% CI 236 to 255) and 351 (253, $95 \%$ CI 326 to 357 ); total protein intake per day (g) was $57(74,95 \%$ CI 49 to 64$)$ and 58 (27, $95 \%$ CI 55 to 60$)$; and total fat intake (g) per day was $37(18,95 \%$ CI 35 to 39 ) and 55 (98, 95\% CI 45 to 65 ), respectively, for T2DM and non-T2DM groups. The mean (SD) of percentage of total energy intake from total $\mathrm{CHO}$ was $64.1(8.2,95 \%$ CI 63.3 to 64.9$)$ and $66.8(9.1,95 \%$ CI 65.9 to 67.7$)$, from protein was $14.3(4.4,95 \%$ CI 13.9 to $14.8)$ and $12.0(3.2,95 \%$ CI 11.7 to 12.3$)$, and from fats was 21.5 (7.9, 95\% CI 20.8 to 22.4$)$ and 21.1 (9.0, 95\% CI 20.3 to 22.0), respectively, for T2DM and non-T2DM groups. There was a significant difference between T2DM and non-T2DM groups $(\Delta 2.7 \pm 8.7 \%, \Delta-2.3$ $\pm 3.9 \%$; $\leq 0.0001)$ for total energy intake from total $\mathrm{CHO}$ and proteins (\% energy). There was no significant difference between T2DM and non-T2DM groups $(\Delta$ $-0.4 \pm 8.5 \% ; \mathrm{p}=0.0637)$ for total energy intake from fats (\% energy). The region-wise mean percentage of total energy intake from macronutrients in T2DM and non-T2DM groups is summarised in figures 1 and 2, respectively. Among the T2DM group $(n=385), 169$ (43.9\%) patients were vegetarian and $216(56.1 \%)$ were on a mixed diet. Similarly, $194(47.3 \%)$ participants were vegetarian and $215(52.6 \%)$ were on a mixed diet in the non-T2DM group $(\mathrm{n}=409)$.

In the T2DM group $(\mathrm{n}=385), 218(56.6 \%)$ participants were advised a diet plan by their physician. The adherence to a prescribed diet was recorded as a yes or no outcome by asking participants whether they adhered to the diet plan. We considered this approach as appropriate due to the cross-sectional nature of this survey. From patients with T2DM who were advised a diet plan $(n=218), 147$ (67.4\%) self-reported adherence. The most common reasons for non-adherence $(n=71)$ were not being bothered about the suggested diet plan (48, $67.6 \%)$, not liking the advised diet $(13,18.3 \%)$, lack of support to prepare the advised diet $(4,5.6 \%)$ and other reasons not specified $(6,8.4 \%)$. The $\mathrm{CHO}$ consumption and glycaemic parameters as per the diet plan adherence is depicted in table 5; however, the relationship between this covariate was not analysed further. 
Table 2 Secondary outcome: summary and comparative analysis of dietary content of T2DM and non-T2DM groups

\begin{tabular}{|c|c|c|c|c|}
\hline & T2DM (N=385) & Non-T2DM (N=409) & $\begin{array}{l}\text { Mean difference } \\
\text { between groupsł }\end{array}$ & p Value \\
\hline \multicolumn{5}{|c|}{ Total calories per day (kcal) } \\
\hline Mean (SD) & $1547.46(610.02)$ & 2132.23 (1892.48) & $584.77(1423.17)$ & $<0.0001 \dagger$ \\
\hline \multicolumn{5}{|c|}{ Total simple CHO per day $(\mathrm{g})$} \\
\hline Mean (SD) & $28.25(44.60)$ & $90.867(149.51)$ & $62.61(111.71)$ & $<0.0001 \dagger$ \\
\hline \multicolumn{5}{|c|}{ Total complex CHO per day $(\mathrm{g})$} \\
\hline Mean (SD) & $217.88(91.48)$ & 259.85 (136.89) & 41.97 (117.09) & $<0.0001 \dagger$ \\
\hline \multicolumn{5}{|c|}{ Total $\mathrm{CHO}$ per day $(\mathrm{g})$} \\
\hline Mean (SD) & 246.13 (91.64) & $350.72(252.95)$ & $104.58(192.44)$ & $<0.0001 \dagger$ \\
\hline \multicolumn{5}{|c|}{ Total proteins per day $(\mathrm{g})$} \\
\hline Mean (SD) & $57.11(74.01)$ & $57.89(27.23)$ & $0.78(55.11)$ & $0.0539 \dagger$ \\
\hline \multicolumn{5}{|c|}{ Total fat per day $(\mathrm{g})$} \\
\hline Mean (SD) & $37.16(18.56)$ & $55.30(98.19)$ & $18.14(71.65)$ & $<0.0001 \dagger$ \\
\hline \multicolumn{5}{|c|}{ Percentage of total energy simple $\mathrm{CHO}(\%)$} \\
\hline Mean (SD) & $7.09(10.85)$ & $13.91(13.86)$ & $6.82(12.49)$ & $<0.0001 \dagger$ \\
\hline \multicolumn{5}{|c|}{ Percentage of total energy complex $\mathrm{CHO}(\%)$} \\
\hline Mean (SD) & $57.00(11.01)$ & $52.92(13.32)$ & $-4.08(12.25)$ & $0.0001 \dagger$ \\
\hline \multicolumn{5}{|c|}{ Percentage of total energy total $\mathrm{CHO}(\%)$} \\
\hline Mean (SD) & $64.09(8.28)$ & $66.83(9.15)$ & $2.74(8.74)$ & $<0.0001 \dagger$ \\
\hline \multicolumn{5}{|c|}{ Percentage of total energy proteins (\%) } \\
\hline Mean (SD) & $14.33(4.45)$ & $12.01(3.23)$ & $-2.32(3.87)$ & $<0.0001 \dagger$ \\
\hline \multicolumn{5}{|c|}{ Percentage of total energy fats (\%) } \\
\hline Mean (SD) & $21.56(7.89)$ & $21.15(9.05)$ & $-0.41(8.51)$ & $0.0637 \dagger$ \\
\hline
\end{tabular}

In our study, the mean (SD) HbAlc $(\%, \mathrm{n}=299)$ was 8.2 (2.0), FBG (mg/dL, $\mathrm{n}=314)$ was $148.2(61.0)$, and $2 \mathrm{~h}$ PPBG $(\mathrm{mg} / \mathrm{dL}, \mathrm{n}=309)$ was $220.0 \quad(90.2)$ in the T2DM group. For glycaemic control as per the $\mathrm{ADA}^{6}$ criteria, of the 299 participants, 33.1\% ( $\mathrm{n}=99)$ had HbAlc $<7 \%$; of the 314 participants, $48.4 \%(\mathrm{n}=152)$ had FBG between 70 and $130 \mathrm{mg} / \mathrm{dL}$; and of the 309 participants, $37.5 \%(\mathrm{n}=116)$ had $2 \mathrm{~h}$ PPBG $<180 \mathrm{mg} / \mathrm{dL}$. This means $66.9 \%, 51.6 \%$ and $62.5 \%$ of the participants had HbA1c, FBG and $2 \mathrm{~h}$ PPBG above the recommended levels.

In the T2DM group, after stratifications as per per cent energy from CHO consumption <50\%, 50-60\% and $>60 \%$, the mean (SD) of $2 \mathrm{~h}$ PPBG $(\mathrm{mg} / \mathrm{dL})$ was 225.0 (91.8), 206.2 (91.6) and 224.5 (89.4), respectively (table 6). There was a trend towards increasing $2 \mathrm{~h}$
PPBG with an increase in $\mathrm{CHO}$ consumption (\% energy) if we consider participants with per cent energy consumption $\geq 50 \%$ from $\mathrm{CHO}(\mathrm{n}=16$, consuming $<50 \%$ of total energy from $\mathrm{CHO}$, hence not considered). However, the current study was not powered to investigate the effect of $\mathrm{CHO}$ consumption and relationship with glycaemic control. We present the observations from our study without doing further analysis considering the various confounder factors like age, sex, BMI, drug therapy, duration of disease, etc. We suggest further research to investigate correlation between \% $\mathrm{CHO}$ consumption and $2 \mathrm{~h}-\mathrm{PPBG}$ and other glycaemic parameters.

The most commonly used antidiabetic medications were metformin $(77.8 \%, \mathrm{n}=298)$, sulfonylureas (SU)

\begin{tabular}{|c|c|c|c|c|c|}
\hline \multirow[b]{2}{*}{ Region } & \multicolumn{5}{|c|}{ T2DM group } \\
\hline & $\mathrm{n}$ & Simple CHO, mean (SD) & Complex CHO, mean (SD) & Total CHO, mean (SD) & Total CHO, g/day (SD) \\
\hline East & 90 & $20.2(9.9)$ & $45.2(8.2)$ & $65.4(6.8)$ & 255 (47) \\
\hline West & 46 & $0.4(1.5)$ & $60.5(7.3)$ & 60.9 (7.3) & 225 (59) \\
\hline North & 80 & $0.9(1.7)$ & $61.8(5.6)$ & $62.7(5.1)$ & 235 (66) \\
\hline South & 79 & 6.8 (12.4) & $55.5(11.7)$ & 62.3 (12.9) & 228 (68) \\
\hline Central & 90 & $3.1(4.6)$ & $64.1(7.7)$ & $67.2(5.6)$ & 273 (151) \\
\hline All & 385 & $7.1(10.8)$ & $57.0(11.0)$ & 64.1 (8.3) & 246 (92) \\
\hline
\end{tabular}

CHO, carbohydrate; T2DM, type-2 diabetes mellitus. 
Table 4 Region-wise mean $\mathrm{CHO}$ (\%, mean (SD) and g/day) intake in the non-T2DM group

\begin{tabular}{|c|c|c|c|c|c|}
\hline \multirow[b]{2}{*}{ Region } & \multicolumn{5}{|c|}{ Non-T2DM group } \\
\hline & $\mathrm{n}$ & Simple CHO, mean (SD) & Complex CHO, mean (SD) & Total CHO, mean (SD) & Total CHO, g/day (SD) \\
\hline East & 90 & $10.3(6.3)$ & $54.3(13.2)$ & $64.6(9.0)$ & 342 (149) \\
\hline West & 70 & $22.7(18.6)$ & 43.7 (16.2) & $66.4(10.8)$ & $523(520)$ \\
\hline North & 80 & $4.4(2.1)$ & $62.9(4.9)$ & $67.3(4.8)$ & $268(82)$ \\
\hline South & 79 & $20.6(17.3)$ & $45.3(9.1)$ & $65.9(13.5)$ & 295 (123) \\
\hline Central & 90 & $13.4(10.4)$ & $56.5(10.8)$ & $69.8(3.9)$ & $347(96)$ \\
\hline All & 409 & $13.9(13.9)$ & $52.9(13.3)$ & $66.8(9.1)$ & 351 (253) \\
\hline
\end{tabular}

$\mathrm{CHO}$, carbohydrate; non-T2DM, non-type-2 diabetes mellitus.

(72.6\%, $\mathrm{n}=278)$, $\alpha$-glucosidase inhibitors (AGIs) $(26.4 \%$, $\mathrm{n}=101)$, thiazolidinedione (TZD) $(24.0 \%, \mathrm{n}=92)$, insulin $(20.6 \%, \mathrm{n}=79)$ and dipeptidyl peptidase-IV inhibitors (DPP4-I) $(13.6 \%, \mathrm{n}=52)$.

\section{DISCUSSION}

Our study shows that T2DM participants belonging to any part of India consume high $\mathrm{CHO}$ in their diet if we compare with dietary recommendations. ${ }^{6} 7$ Our study showed that $64.1 \pm 8.3 \%$ (95\% CI 63.27 to 64.93$)$ of total calories came from total $\mathrm{CHO}$ in the T2DM group. This suggests that $\mathrm{CHO}$ consumption by T2DM participants in India is higher $(\Delta 4.1 \%$ above the upper limit of $60 \%)$ than that recommended by the guidelines ${ }^{67}$ and within the recommended limits as per the WHO expert consensus. ${ }^{9}$ Recently, Sivasankari et $a l^{4}$ reported a similar dietary pattern of T2DM participants from south India (CHO $\sim 65 \%, \mathrm{P} \sim 11.5 \%$, and $\mathrm{F} \sim 23.5 \%$ ). Studies from the West $^{10}$ reported just 39-49\% energy intake from $\mathrm{CHO}$ in the diet, which is much lower than that reported in our study. This further shows that our participants consume high $\mathrm{CHO}$ in their diet compared to the western population. T2DM participants seem to be well aware of the importance of restricting the consumption of simple $\mathrm{CHO}$ to $<10 \%$ as per the recommendations of NIN, ${ }^{6}$ the Indian consensus statement, ${ }^{7}$ and the WHO expert recommendations ${ }^{8}(7.1 \pm 10.8 \%$ (95\% CI 6.0 to 8.2 ) of total energy came from simple $\mathrm{CHO})$. In region-wise analysis, only the eastern region reported a
Figure 1 Regionwise macronutrient composition in the type-2 diabetes mellitus group (\% energy intake).


intake in T2DM group
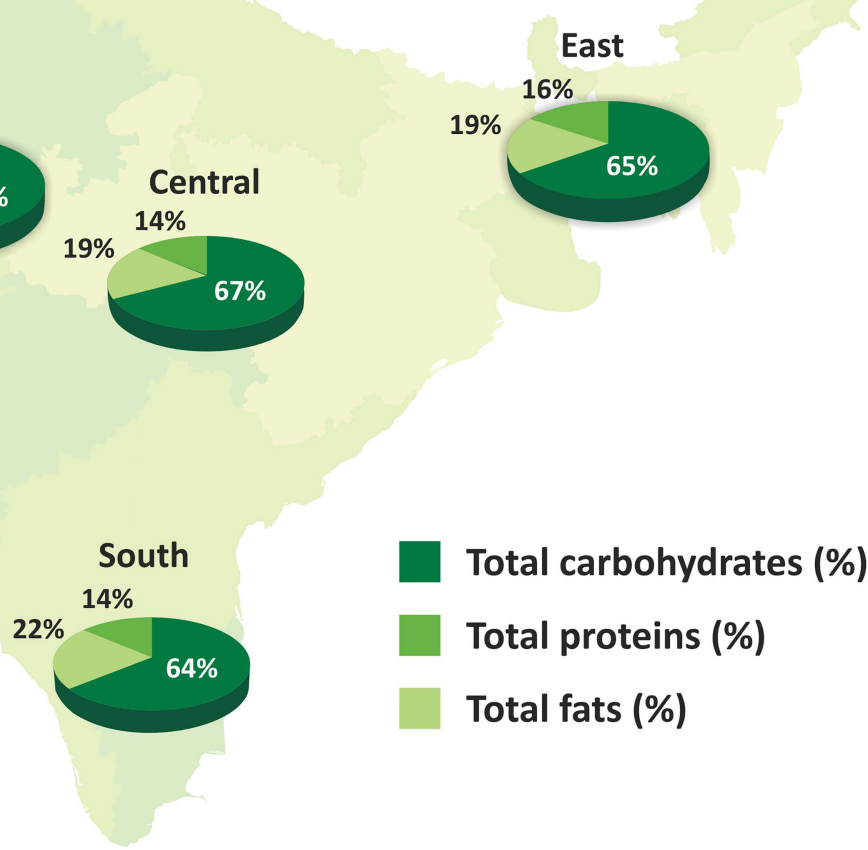

Total carbohydrates (\%)

Total proteins (\%)

Total fats (\%) 


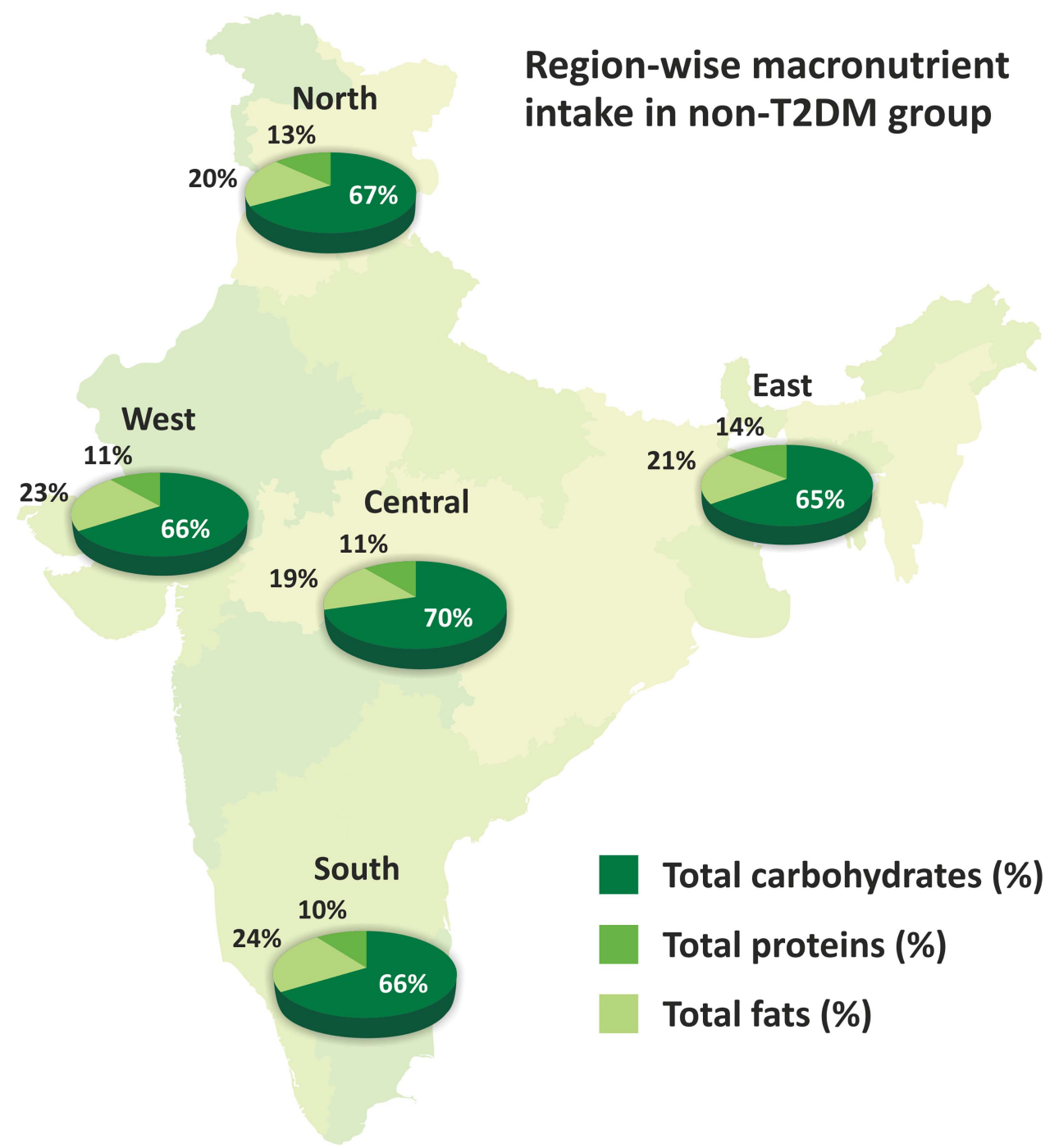

Figure 2 Regionwise macronutrient composition in the non- type-2 diabetes mellitus group (\% energy intake).

higher consumption of simple CHO $(20.2 \pm 10.0 \%, 95 \%$ CI 18.1 to 22.3); subsequently, a lower consumption of complex $\mathrm{CHO}(45.2 \pm 8.2 \%$, 95\% CI 43.5 to 47.0$)$ was observed. This reflects the typical dietary pattern of participants from eastern India.

Total calorie intake $(1547.5 \pm 610.0 \mathrm{kcal}, \quad 95 \%$ CI 1486.3 to 1608.6 ) appears in the recommended range of daily allowance in the T2DM group (1329$1993 \mathrm{kcal} /$ day, considering mean weight $(66.45 \mathrm{~kg})$ and caloric requirements $(20-30 \mathrm{kcal} / \mathrm{kg} /$ day $)$ as per Misra et $a l^{7}$ In the non-T2DM group $(\mathrm{n}=409), 66.8 \pm 9.1 \%$ (95\% CI 65.9 to 67.7$)$ of total energy came from total CHO. The difference between T2DM and non-T2DM groups was $2.7 \% \quad(\mathrm{p}<0.001)$. As expected, the non-T2DM group consumed simple $\mathrm{CHO}$ at a higher level than the recommended level $(13.9 \pm 13.9 \%, 95 \%$ CI 11.1 to 15.3 ) and had a relatively lower consumption of complex $\mathrm{CHO}(52.9 \pm 13.3 \%, 95 \%$ CI 51.6 to 54.2$)$. These findings were similar to those reported earlier by Radhika et al. ${ }^{11}$

The comparison of macronutrients (ie, region-wise $\mathrm{CHO}$, fat and protein) revealed a similar pattern of dietary consumption, that is, high $\mathrm{CHO}$ and a lower range of fat and protein (figure 1). This study neutralises the myth that only the south Indian population consumes high $\mathrm{CHO}$ in their diet (rice, idli and so on). A similar dietary pattern was also reported in non-T2DM participants (figure 2).

Our study shows that only $38.1 \%$ of total T2DM participants $(\mathrm{n}=385$, refer table 5$)$ adhere to a diet. This finding is similar (37\%, adherence to diet) to that in a study reported by Shobana et $a l^{12}$ earlier from south India. Moreover, adherence to the diet plan was higher $(64.4 \%$, $\mathrm{n}=218$, refer table 5) in T2DM participants who were advised a diet plan by their physicians, but a little lower than that reported by Patel et $a l^{13}(73 \%)$ in a study from western India. These data further suggest the need for all people with T2DM to receive regular nutritional counselling from a dietitian/physicians. We suggest that people with T2DM should be encouraged to achieve optimal metabolic control through a balance of food intake, physical activity and medication to avoid long-term complications. Most importantly, specific dietary recommendations should be individualised to accommodate the person's 
Table $5 \mathrm{CHO}$ consumption and glycaemic parameters with respect to diet plan adherence in the T2DM group

\begin{tabular}{|c|c|c|c|}
\hline \multirow[b]{3}{*}{ Parameters } & \multicolumn{3}{|l|}{ Diet plan } \\
\hline & \multicolumn{2}{|l|}{ Advised (n=218) } & \multirow[b]{2}{*}{ Not advised $(n=167)$} \\
\hline & Adherent to diet $(n=147)$ & Not adherent to diet $(n=71)$ & \\
\hline Total $\mathrm{CHO}$ intake (\%, SD) & $63.4(9.3)$ & $60.4(7.1)$ & $66.2(6.9)$ \\
\hline Complex $\mathrm{CHO}$ intake (\%, SD) & $54.1(11.9)$ & $56.1(9.4)$ & $60.0(10.1)$ \\
\hline Simple $\mathrm{CHO}$ intake $(\%, \mathrm{SD})$ & $9.4(13.2)$ & $4.3(7.4)$ & $6.2(9.3)$ \\
\hline $\mathrm{FBG}(\mathrm{mg} / \mathrm{dL})$ & $n=100$ & $\mathrm{n}=61$ & $n=153$ \\
\hline mg/dL, mean (SD) & $146.1(62.0)$ & $142.2(54.4)$ & $151.8(62.9)$ \\
\hline Control level $^{*}(70-100 \mathrm{mg} / \mathrm{dL})(\mathrm{n},(\%))$ & $52(35.4)$ & $30(42.3)$ & $70(41.9)$ \\
\hline PPBG (mg/dL) & $\mathrm{n}=97$ & $\mathrm{n}=60$ & $\mathrm{n}=153$ \\
\hline mg/dL, mean (SD) & $220.2(78.7)$ & $212.1(100.6)$ & $223.1(93.0)$ \\
\hline Control level ${ }^{\star}(<180$ mg/dL) (n, (\%)) & $34(23.1)$ & $29(40.8)$ & $53(31.7)$ \\
\hline $\mathrm{HbA1c}(\%)$ & $n=96$ & $n=59$ & $n=1544$ \\
\hline Per cent, mean (SD) & $8.0(1.7)$ & $7.8(1.8)$ & $8.4(2.2)$ \\
\hline Control level $^{*}(<7 \%)(\mathrm{n},(\%))$ & $27(18.4)$ & $26(36.6)$ & $46(27.5)$ \\
\hline
\end{tabular}

${ }^{*}$ As per ADA criteria, ${ }^{5}$ that is, $\mathrm{HbA} 1 \mathrm{c}<7 \%$, FBG between 70 and $130 \mathrm{mg} / \mathrm{dL}$, and PPBG $<180 \mathrm{mg} / \mathrm{dL}$.

$\mathrm{ADA}$, American Diabetes Association; $\mathrm{CHO}$, carbohydrate; FBG, fasting blood glucose; HbA1c, glycated hemoglobin; PPBG, postprandial blood glucose; T2DM, type-2 diabetes mellitus.

preferences and lifestyle to enhance the acceptance and adherence to the diet plan.

The cross-sectional study provides a good opportunity to assess glycaemic control in T2DM participants. In our study, 66.9\% of T2DM participants had HbA1c above the targeted 7\% (non-adjusted for co-variables). Patel et $a l^{13}$ reported similar findings in their study $(35 \%$ had HbA1c <7\%). In T2DM participants, higher blood glucose levels may reflect poor compliance to therapy, poor physical activity, poor awareness of cut-off points, importance of diet and so on. Engaging the physicians, trained dietician and people with diabetes for increasing awareness of lifestyle changes to prevent long-term complications is clearly warranted.

The amount of CHO consumed affects blood glucose levels and insulin responses. ${ }^{7}$ In our study, there was a trend (non-significant) towards higher consumption of CHO with high $2 \mathrm{~h}$ PPBG levels. Manobala et $a l^{14}$ reported that an increase in dietary $\mathrm{CHO}(\%$ of

Table 6 Glycaemic level after stratification by per cent energy from $\mathrm{CHO}$ consumption in the T2DM group (descriptive observation)

\begin{tabular}{|c|c|c|c|}
\hline \multirow{2}{*}{$\begin{array}{l}\text { Blood glucose } \\
\text { parameters }\end{array}$} & \multicolumn{3}{|c|}{$\begin{array}{l}\text { Percentage of total energy } \\
\text { intake from } \mathrm{CHO} \text { stratification }\end{array}$} \\
\hline & $<50 \%$ & $50-60 \%$ & $>60 \%$ \\
\hline $\begin{array}{l}\text { FBG (mg/dL) mean } \\
\text { (SD) }(n=314)\end{array}$ & $\begin{array}{l}150.8 \\
(61.6) \\
n=16\end{array}$ & $\begin{array}{l}147.0 \\
(65.6) \\
n=76\end{array}$ & $\begin{array}{l}148.3 \\
(59.6) \\
n=222\end{array}$ \\
\hline $\begin{array}{l}\text { PPBG (mg/dL) mean } \\
\text { (SD) }(n=309)\end{array}$ & $\begin{array}{l}225.0 \\
(91.8) \\
n=16\end{array}$ & $\begin{array}{l}206.2 \\
(91.6) \\
n=77\end{array}$ & $\begin{array}{l}224.5 \\
(89.4) \\
n=216\end{array}$ \\
\hline $\begin{array}{l}\mathrm{HbA1c}(\%) \text { mean }(\mathrm{SD}) \\
(\mathrm{n}=299)\end{array}$ & $\begin{array}{l}8.2(1.2) \\
n=16\end{array}$ & $\begin{array}{l}8.0(1.8) \\
n=78\end{array}$ & $\begin{array}{l}8.2(2.1) \\
n=205\end{array}$ \\
\hline
\end{tabular}

$\mathrm{CHO}$, carbohydrate; FBG, fasting blood glucose; HbA1c, glycated hemoglobin; PPBG, postprandial blood glucose; T2DM, type-2 diabetes mellitus. energy), glycaemic load and weighted glycaemic index was associated with an increase in HbAlc levels.

In our study, the most commonly prescribed antidiabetic drug class was metformin $(77.8 \%)$ followed by sulfonylurea $(72.6 \%)$, $\alpha$-glucosidase inhibitors $(26.4 \%)$, thiazolidinedione $(24.0 \%)$, insulin $(20.6 \%)$ and dipeptidyl peptidase-IV inhibitors (13.6\%). A similar pattern of drug use was reported earlier in a small study from northern India. ${ }^{15}$

Our study shows that T2DM participants consume high $\mathrm{CHO}$ in their diet, which has a direct effect on postprandial blood glucose and insulin response. ${ }^{7}$ In addition to dietary and lifestyle modifications, multiple therapeutic strategies like AGIs, SU, Insulin, DPP4-I and glucagon-like-peptide-1 analogues may benefit T2DM participants. Metformin was the most commonly used antidiabetic agent in our study. It is a hypoglycaemic agent that has been widely used in clinical practice for more than half a decade to treat diabetes. It is as safe and effective as monotherapy and can also be used in combination with any other hypoglycaemic agent for treatment of diabetes. Furthermore, it is cost-effective, reduces weight and is weight neutral. It has less incidence of hypoglycaemia as compared to sulfonylurea and insulin and exerts beneficial effects on lipids. ${ }^{1617}$ The second most commonly used medication was sulfonylurea. Among sulfonylureas, glimepiride was the one most commonly used. The higher usage of sulfonylurea is probably due to the need to rapidly control the glucose levels and the preference for glimepiride could be due to its lower propensity to cause hypoglycaemia. The next commonly used agents were AGIs (acarbose and voglibose) in our study. AGIs such as acarbose seem to be particularly useful in newly diagnosed T2DM with excessive PPBG, because of their unique mode of action, that is, to delay digestion and absorption of complex $\mathrm{CHO}$ and reduce postprandial rise in blood glucose levels. ${ }^{18} 19$ Usage of AGIs seems to be more in our study compared to that reported previously ( $26.4 \%$ in our 
study vs $7.6 \%$ in Sultana $\left.e t a l^{15}\right)$. In an editorial published in the November 2010 issue of the Journal of Association of Physicians of India, ${ }^{20}$ the author expressed the need for therapeutic agents like AGIs that reduce postprandial hyperglycaemia and hyperinsulinaemia and also increase incretin levels (glucagon-like peptide-1) early in the course of T2DM. This strategy may have a more prominent role in an Indian setting where the role of AGIs is even more significant as meal component is rich in $\mathrm{CHO}$ as seen in this study. ${ }^{20}$ However, we need to investigate further the benefit of various therapeutic interventions in high CHO-consuming Indian T2DM participants in a prospective randomised controlled study to examine this hypothesis.

\section{LIMITATION}

This study has some limitations; the cross-sectional design of the study does not allow us to make inferences about the cause (consumption of high $\mathrm{CHO}$ ) and effect (glycaemic control, rise in PPBG). Another possible limitation of the study includes the small sample size, the possibility of measurement error of diet and covariates. A more detailed analysis of the diet (qualitative) was not planned in this study, which could provide more useful information about the quality and quantity of $\mathrm{CHO}$ consumed at various meals during a typical day. We did not perform repeat studies and therefore could not verify the accuracy of our findings. We would like to conduct the post hoc analysis of diet using the available data to further enhance the knowledge on this aspect. Subject flow was mostly from specialty endocrinology/diabetology centres from urban areas and may not completely represent the actual T2DM participants in India.

\section{CONCLUSION}

Data from the present cross-sectional study show that CHO constitutes $64.1 \%$ of total energy from diet in the T2DM group, which is higher than the recommended level. There was clear non-adherence (self-reported) to dietary advice in the T2DM group. Our findings need to be confirmed in a larger epidemiological survey.

\footnotetext{
Author affiliations

${ }^{1} J o s h i$ Clinic, Mumbai, Maharashtra, India

${ }^{2}$ Postgraduate Institute of Medical Education and Research, Chandigarh, India

${ }^{3}$ MLN Medical College, Allahabad, Uttar Pradesh, India

${ }^{4}$ Subodh Banzal's Clinic, Indore, Madhya Pradesh, India

${ }^{5}$ Bangalore Endocrinology and Diabetes Research Center Pvt Ltd, Bangalore, Karnataka, India

${ }^{6}$ Krishna Diabetes Clinic and Educational Research Centre, Bhopal, Madhya Pradesh, India

${ }^{7}$ Institute of Post Graduate Medical Education and Research, Kolkata, West Bengal, India

${ }^{8}$ Gujarat Endocrine Centre, Ahmedabad, Gujarat, India

${ }^{9}$ Sahay's Endocrine and Diabetes Clinic, Hyderabad, Andhra Pradesh, India

${ }^{10}$ Sarkar's Diabetes Nutrition Clinic and Research Center, Agartala, Tripura, India

${ }^{11}$ Department of Medical Affairs, Bayer Zydus Pharma Private Limited, Thane,

Maharashtra, India

${ }^{12}$ Mumbai Diet and Health Center, Mumbai, Maharashtra, India
}

Acknowledgements The authors thank Makrocare CRO for providing data management, statistical analysis and medical writing support.

Contributors SRJ, RR and PVM were involved in the study concept; study design; data collection and analysis; and manuscript writing, review and finalisation. AB, SB, SSB, MD, SG, SM, PRS, RS and SS were involved in data collection and analysis, as well as in reviewing the manuscript. SSJ was involved in the study design, data analysis related to dietary survey, development and validation of the dietary survey and review of the manuscript.

Funding Study sponsor (Bayer Zydus Pharma, India) was involved in the study concept; study centre selection, study design; collection, analysis and interpretation of data; and in the decision to submit the article for publication. Makrocare was contracted by the sponsor for data management, statistical analysis and medical writing.

Competing interests SRJ: Author. Bayer Zydus Pharma; Speaker. Sanofi, Abbott, USV, Franco Indian, Ranbaxy, PHFI, MSD, Novartis, J \& J, Roche Diagnostics, Novo Nordisk, Marico, Emcure; Consultant, Investigator. Bayer Zydus Pharma; Research Support. Bayer Zydus Pharma; AB: Research Grant. Bayer Zydus Pharma; SB: Investigator. Bayer Zydus Pharma; SSB: Investigator. Bayer Zydus Pharma; MD: Research Grant. Bayer Zydus Pharma; SG: Investigator. Bayer Zydus Pharma; SM: Investigator. Bayer Zydus Pharma; PRS: Advisor, Speaker, Investigator. Bayer Zydus Pharma; RS: Author, Investigator. Bayer Zydus Pharma; Advisor. Sanofi, Eli Lily; Advisor, Author. Nova Nordisk; Speaker. USV India, Alkem; SS: Investigator. Bayer Zydus Pharma; SSJ: Author, Consultant, Investigator. Emcure, Bayer Zydus Pharma; RTR \& PVM: Author, Employee: Bayer Zydus Pharma, India. Bayer Zydus pharma markets acarbose in India.

Ethics approval The study was conducted in accordance with principles of Good Clinical Practice and was approved by the ethics committee. Independent ethics committee: Clinicom Bangalore; Institutional ethics committee: PGI Chandigarh; Bangalore Endocrinology \& Diabetes Research Centre; IPGME\&R Research Oversight Committee.

Provenance and peer review Not commissioned; externally peer reviewed.

Data sharing statement No additional data are available.

Open Access This is an Open Access article distributed in accordance with the Creative Commons Attribution Non Commercial (CC BY-NC 4.0) license, which permits others to distribute, remix, adapt, build upon this work noncommercially, and license their derivative works on different terms, provided the original work is properly cited and the use is non-commercial. See: http:// creativecommons.org/licenses/by-nc/4.0/

\section{REFERENCES}

1. Mohan V. Why are Indians more prone to diabetes? J Assoc Physician India 2004;52:468-74.

2. Gopalan C. Rising incidence of obesity, coronary heart disease and diabetes in the Indian urban middle class possible. Role of genetic and environmental factors. World Rev Nutr Diet 2001;90:127-43.

3. Radhika G, Sathya RM, Sudha V, et al. Dietary salt intake and hypertension in an urban south Indian population. J Assoc Physician India 2007;55:405-11.

4. Sivasankari V, Manobala K, Geetha G, et al. Dietary profile of Chennai urban adults with diabetes. Poster at RSSDI 2012 (Abstract).

5. American Diabetes Association. Standards of medical care in diabetes-2013. Diabetes Care 2013;36(Suppl 1):S11-66.

6. National Institute of Nutrition. Dietary guideline for Indians-a manual. 2nd edn. 2010. http://www.ninindia.org/ Dietaryguidelinesforlndians-Finaldraft.pdf (accessed 25 Mar 2013)

7. Misra A, Sharma R, Gulati S, et al. Consensus dietary guidelines for healthy living and prevention of obesity, the metabolic syndrome, diabetes, and related disorders in Asian Indians. Diabetes Technol Ther 2011;13:683-94.

8. Mann J. Dietary carbohydrate: relationship to cardiovascular disease and disorders of carbohydrate metabolism. Eur J Clin Nutr 2007;61 (Suppl 1):S100-11.

9. SSL Parashar. Principles of sociology in health care, section 4: social, behavioral and communication sciences. In: Bhalwar R ed. Textbook on public health and community medicine. New Delhi, India: Department of Community Medicine Armed Forces Medical College Pune in collaboration with WHO India, 2009:608-13. 
10. Esposito K, Maiorino MI, Palo CD, et al. Dietary glycemic index and glycemic load are associated with metabolic control in type-2 diabetes: the CAPRI experience. Metab Syndr Relat Disord 2010;8:255-61.

11. Radhika G, Sathya RM, Sudha V, et al. Dietary salt intake and hypertension in an urban south Indian population. J Assoc Physician India 2007;55:405-11.

12. Shobana R, Begum R, Snehalatha $C$, et al. Patient's adherence to diabetes treatment. J Assoc Physicians India 1999;47:1173-5.

13. Patel M, Patel IM, Patel YM, et al. Factors associated with consumption of diabetic diet among type 2 diabetic subjects from Ahmedabad, Western India. J Health Popul Nutr 2012; 30:447-55.

14. Manobala K, Lakshmipriya N, Vijayalakshmi P, et al. Association of dietary carbohydrates and refined cereal consumption with glycemic control among Chennai urban adults with diabetes. Poster at RSSDI 2012 (Abstract).
15. Sultana G, Kapur P, Aqil M, et al. Drug utilization of oral hypoglycemic agents in a university teaching hospital in India. J Clin Pharm Ther 2010;35:267-77.

16. Ali S, Fonseca V. Overview of metformin: special focus on metformin extended release. Expert Opin Pharmacother 2012;13:1797-805.

17. Bennett WL, Maruthur NM, Singh S, et al. Comparative effectiveness and safety of medications for type 2 diabetes: an update including new drugs and 2-drug combinations. Ann Intern Med 2011:154:602-13.

18. Hanefeld M. Acarbose revisited for efficacy, safety and cardiovascular benefits: a key role for controlling glycemic variability. Expert Rev Endocrinol Metab 2012;7:395-405.

19. Derosa G, Maffioli P. $\alpha$-Glucosidase inhibitors and their use in clinical practice. Arch Med Sci 2012;8:899-906.

20. Joshi SR. Editorial: post-prandial carbohydrate modulation via gutIndian perspective. J Assoc Physician India 2010;58:665 